\title{
Syncope: epidemiology, etiology, and prognosis
}

\section{Rose M. F. L. da Silva *}

Department of Internal Medicine, Faculty of Medicine, Federal University of Minas Gerais, Belo Horizonte, Brazil

\section{Edited by:}

Leonardo Roever, University of São

Paulo and Federal University of

Uberlândia, Brazil

Reviewed by:

Nazareno Paolocci, The Johns

Hopkins University, USA

Helio Cesar Salgado, University of

São Paulo, Brazil

Jose Antonio Franchini Ramires,

University of São Paulo, Brazil

\section{*Correspondence:}

Rose M. F. L. da Silva, Department of Internal Medicine, Faculty of Medicine, Federal University of Minas Gerais, Avenue Alfredo Balena, 190, Room 246, Santa

Efigênia, Belo Horizonte 30.130-100,

Minas Gerais, Brazil

e-mail:roselisboa@uol.com.br
Syncope is a common medical problem, with a frequency between $15 \%$ and $39 \%$. In the general population, the annual number episodes are 18.1-39.7 per 1000 patients, with similar incidence between genders. The first report of the incidence of syncope is 6.2 per 1000 person-years. However, there is a significant increase in the incidence of syncope after 70 years of age with rate annual 19.5 per thousand individuals after 80 years. It presents a recurrence rate of $35 \%$ and $29 \%$ of physical injury. Among the causes of syncope, the mediated neural reflex, known as neurocardiogenic or vasovagal syncope, is the most frequent. The others are of cardiac origin, orthostatic hypotension, carotid sinus hypersensitivity, neurological and endocrinological causes and psychiatric disorders. The diagnosis of syncope can be made by clinical method associated with the electrocardiogram in up $50 \%$ of patients. Its prognosis is determined by the underlying etiology specifically the presence and severity of cardiac disease. The annual mortality can reach between 18 and $33 \%$ if cardiac cause, and between 0 and $12 \%$ if the non-cardiac cause. Thus, it is imperative to identify its cause and risk stratification for positive impact in reducing morbidity and mortality.

Keywords: vasovagal syncope, cardiac arrhythmias, orthostatic intolerance, epidemiology, prognosis

\section{DEFINITION AND EPIDEMIOLOGY}

Syncope is the sudden loss of consciousness, associated with inability to maintain postural tone, with immediate and spontaneous recovery without requiring electrical or chemical cardioversion. This framework is secondary to cerebral hypoperfusion, with short duration (average 12 seconds). It has a prevalence of $42 \%$, considering a life time of 70 years and an annual incidence of 6\% (Moya et al., 2009). Its frequency varies from $15 \%$ (below 18 years of age) (Lewis and Dhala, 1999) to 39\% (among medical students) (Serletes et al., 2006), reaching 23\% among the elderly (Lipsitz et al., 1985). In the general population, the annual number episodes are 18.1-39.7 per 1000 patients, with similar incidence between genders, and with high prevalence between 10 and 30 years of age, mainly of vasovagal syncope (Moya et al., 2009). The first report of the incidence of syncope is 6.2 per 1000 person-years. However, there is a significant increase in the incidence of syncope after 70 years of age, with 5.7 episodes/1000 individuals per year between 60 and 69 years old and with 11.1 episodes/1000 individuals per year between 70 and 79 years age. After 80 years, the annual incidence may reach 19.5 per 1000 individuals (Soteriades et al., 2002; Colman et al., 2004).

This framework is responsible for 3-5\% of emergency department visits, with a hospitalization rate in about $40 \%$ of cases, with an average stay of 5.5 days. Beyond this morbidity, there is a recurrence rate of approximately $35 \%$ and $29 \%$ of physical injury, and major trauma in $4.7 \%$ of patients. In elderly patients with syncope due to carotid sinus hypersensitivity, the prevalence of trauma may reach 43\% (Brignole et al., 2006; Moya et al., 2009). Besides the social impact with worsening quality of life, there is also the economic impact, with higher costs attributed to hospitalization with an estimated $\$ 2.4$ billion annual cost (Sun, 2013).

\section{ETIOLOGY}

Among the causes of syncope, the mediated neural reflex, known as neurocardiogenic or vasovagal syncope, is the most frequent, accounting for one third of the causes and reaching $66 \%$ of cases in emergency units (Alboni et al., 2001; Brignole et al., 2006). The diagnosis of syncope can be made by clinical method associated with the electrocardiogram in up 50\% of patients (Moya et al., 2009). The clinical history should be performed with proficiency, and each episode of syncope should be well characterized about presence of prodrome, precipitating factors, conditions in which it occurred, position of the patient, and other associated signs such as nausea, pallor, diaphoresis, muscle twitching, confusion, physical injury, palpitations, dyspnea, chest pain, and cyanosis. The personal medical history and family history are also important to identify the cause of syncope. The Calgary Score is one of the diagnostic tools, including seven clinical issues and allow diagnosis vasovagal syncope with $89 \%$ sensitivity and $91 \%$ specificity (Sheldon et al., 2006). The physical examination should be comprehensive, including measurement of blood pressure in the supine position and within $3 \mathrm{~min}$ in the orthostatic position, the blood pressure measurements in both arms (to detect subclavian steal), and the exam of the cardiovascular system, which can identify signs of disease and/or arrhythmias, and other systems.

The main causes of syncope are summarized in Table 1 and will be discussed below. 
Table 1 | Common causes of syncope.

\begin{tabular}{ll}
\hline $\begin{array}{l}\text { Pathophysiological } \\
\text { origin }\end{array}$ & Causes \\
\hline Reflex syncope & $\begin{array}{l}\text { Vasovagal, situational syncope, orthostatic } \\
\text { hypotension, carotid sinus hypersensitivity } \\
\text { Structural heart disease, bradyarrhythmias, } \\
\text { tachyarrhythmias }\end{array}$ \\
Neurological causes & $\begin{array}{l}\text { Cerebrovascular disease, autonomic } \\
\text { dysfunction, subclavian steal syndrome } \\
\text { Others causes }\end{array}$ \\
& $\begin{array}{l}\text { Endocrinological causes, psychiatric } \\
\text { disorders }\end{array}$ \\
\end{tabular}

\section{VASOVAGAL SYNCOPE}

This term was first used by William Gowers in 1907 and described the mechanism of vasovagal syncope by Thomas Lewis in 1932 (Lewis, 1932). It shows bimodal distribution, but is most common in young people. Precipitating factors are prolonged sitting position or standing position, emotional stress, pain, heat, venous puncture, alcohol use, dehydration, use of diuretics and vasodilators. Prodromes of nausea, vomiting, abdominal pain, diaphoresis, pallor, palpitations, and dizziness may occur and are more common in young people. After loss of consciousness, tonicclonic contractions, if they occur, are of short duration $(<15 \mathrm{~s})$. There are no aura, headache, sleep, sphincter release, mental confusion, and duration of loss of consciousness greater than $5 \mathrm{~min}$, such as occurs in epilepsy (Kapoor, 2002; Moya et al., 2009). The neuromediated syncope is called situational syncope when it occurs in conditions that trigger the Valsalva maneuver, such as urination, defecation, coughing, visceral pain, carry weight.

The mechanism of vasovagal syncope is explained by the Bezold-Jarisch reflex, which is triggered due to decreased venous return resulting in inadequate ventricular filling and vigorous cardiac contraction. It occurs by the action of mechanoreceptors (C fibers) preferentially located in the inferolateral wall of the left ventricle, but also in the atria and in the pulmonary artery, and manifests with hypotension and paradoxical bradycardia due to increased activity of inhibitory receptors and consequent parasympathetic hyperactivity (Medow et al., 2008; Moya et al., 2009).

Initial therapy of vasovagal syncope is non-pharmacological. The recommendations are to identify and avoid the precipitating factors, assuming the supine position during the period of prodromes, and nutritional guidelines. These include hydration with fluid intake 2-2.5 liters per day and sodium supplementation. Aerobic and isometric exercises of the upper and lower limbs reduce the recurrence of vasovagal syncope. Tilt training compared with conventional treatment shows limited efficacy in controlled studies. The use of compression stockings in the lower limbs may be recommended, however it has limited efficacy and poor adherence. If failure of initial recommendations, the next step is pharmacological treatment with the use of fludrocortisone if vasodepressor response. Beta blockers are contraindicated. Implantation of a pacemaker is class IIa indication for patients over 40 years of age and cardioinhibitory response with asystole (Moya et al., 2009; Raj and Coffin, 2013).

\section{CARDIAC CAUSES}

The causes are structural heart diseases or conditions that result in decreased cardiac output such as aortic stenosis, hypertrophic cardiomyopathy, ischemic heart disease, heart failure, aortic dissection, cardiac tamponade, prosthetic valve thrombosis, cardiac tumors, pulmonary hypertension, pulmonary embolism etc. Both bradyarrhythmias and tachyarrhythmias are frequent causes of cardiac syncope due to impaired cardiac output secondary to the frequency of the arrhythmia, its origin, to systolic ventricular dysfunction. A family history of sudden cardiac death is an important data for the hypothesis channelopathy (Moya et al., 2009; Rosanio et al., 2013). Treatment depends on the cause cardiac syncope, with treatment directed to the structural heart disease, pacemaker implantation, if bradyarrhythmias, or use of antiarrhythmic, catheter ablation or implantable cardioverter-defibrillator, if tachyarrhythmias (Moya et al., 2009).

\section{ORTHOSTATIC HYPOTENSION}

Orthostatic or postural hypotension $(\mathrm{OH})$ presents as falls, dizziness, or syncope, resulting in functional impairment, with head injury, bone fractures and hospitalization. It is more common in the elderly, with frequency rates of up to $55 \%$ in those that residing in institutions, and with prevalence of $12 \%$. Its classic definition is a drop of at least $20 \mathrm{mmHg}$ in systolic and/or $10 \mathrm{mmHg}$ in diastolic blood pressure within $3 \mathrm{~min}$ to take an orthostatic position. There are other presentations such as initial $\mathrm{OH}$, when there is a greater than $40 \mathrm{mmHg}$ drop in blood pressure, with less than $30 \mathrm{~s}$ in duration, and progressive $\mathrm{OH}$, when the fall of blood pressure levels are gradual, between 3 and $30 \mathrm{~min}$ after taking standing position, without bradycardia (Goldstein and Sharabi, 2009; Moya et al., 2009).

Beyond the control of the precipitating factor, hydration and salt intake, treatment of syncope postural hypotension can be done with fludrocortisone, midodrine. Other measures are abdominal compression and elevation of the head of the bed (Moya et al., 2009; Raj and Coffin, 2013).

Postprandial hypotension is a common cause of syncope in the elderly, with a prevalence that can reach $67 \%$, especially in the elderly who live in institutions. It is defined as the drop of at least $20 \mathrm{mmHg}$ in systolic blood pressure or absolute value of the systolic pressure lower than $90 \mathrm{mmHg}$ (those with systolic blood pressure of at least $100 \mathrm{mmHg}$ ), within $2 \mathrm{~h}$ after meals. The pathophysiology is due to sympathetic dysfunction, with inadequate peripheral vasoconstriction and insufficient heart rate increase. Precipitating factors are vasodilators, high temperature of food or of environment and diets high in carbohydrates (Luciano et al., 2010).

\section{CAROTID SINUS HYPERSENSITIVITY}

It is an extrinsic sinus node disease that is characterized by pre-syncope or syncope exacerbated by the carotid sinus reflex response. Its incidence is 35-40 patients/year/million individuals, with a predominance in males (male:female ratio of $4: 1$ ) and more frequent in the elderly, especially diabetics with coronary or carotid atherosclerosis. Precipitating factors are sudden movements of the head and neck, cervical compressions and use of tight neck tie (Healey et al., 2004). The approach of the 
carotid sinus syndrome includes the implantation of a pacemaker if cardioinhibitory response, or use of volumetric expansion, if vasodepressor response.

\section{NEUROLOGICAL CAUSES}

Neurological causes are cerebrovascular disease, autonomic dysfunction and subclavian steal syndrome. Focal neurological deficits in stroke, vertebrobasilar transient ischemic stroke, migraine (for vasospasm or vasovagal reflex) may be presented as syncope.

The primary autonomic dysfunction occurs in pure primary dysfunction syndrome (Bradbury-Eglleston), in central nervous system diseases (Parkinson's disease, multiple system atrophy or Shy-Drager syndrome, Huntington's disease and Guillain-Barré syndrome). Secondary dysfunctions occur by changes of aging, due to the involvement of the peripheral nervous system in diabetes mellitus, renal failure, alcoholism, amyloidosis; infections of the nervous system by Chagas disease, human immunodeficiency virus; metabolic diseases such as vitamin B12 deficiency, porphyria; autoimmune diseases such as rheumatoid arthritis and others. And as antihypertensive drugs (diuretics, vasodilators), anti-depressants may also cause autonomic dysfunction (Azhar and Lipsitz, 1998).

The first report of subclavian steal syndrome was described in 1960 by Contorni. It shows a prevalence of up to $6.4 \%$. There is malformation or obstruction by atherosclerosis of the proximal subclavian artery to the origin of vertebral artery, resulting in retrograde flow in this artery. It occurs mainly in the left subclavian artery. Neurological symptoms, such as dizziness, paresthesia and syncope, occur during exercise performed by the arm, but patients may present framework of transient ischemic attacks (Osiro et al., 2012; Potter and Pinto, 2014).

\section{OTHERS CAUSES}

There are endocrinological causes that can be presented as orthostatic hypotension to cause autonomic dysfunction or hypovolemia. As examples, chronic adrenal insufficiency and hypopituitarism can be cited. Diabetes insipidus and saltlosing nephropathies since they result in volume depletion, and pheochromocytoma and carcinoid syndrome, due to vasoactive substances, can also be causes of syncope. Hyperventilation and psychiatric disorders, due to cerebral hypoperfusion, are other causes of syncope (Kapoor, 2002; Moya et al., 2009).

\section{PROGNOSIS}

The pathophysiology, approach, prognosis and treatment depend on the cause of syncope, and mandatory their identification, since their annual mortality can reach between 18 and 33\% if cardiac cause, and between 0 and 12\% if the non-cardiac cause (Kapoor, 2002).

There are studies that compared mortality among patients with syncope of cardiac origin and non-cardiac origin. Among participants in the Framingham heart Study, 7814 patients were included from 1971 to 1998 and 822 presented syncope of which 9.5\% were cardiac. Adjusted multivariate analysis showed that the risk of death increased by $31 \%$ among all patients with syncope and was doubled among those with syncope of cardiac origin, compared with those without syncope. Neurological cause of syncope was also associated with a threefold risk of stroke. Moreover, there was no association with death or major adverse events among those with vasovagal syncope (Soteriades et al., 2002).

In the study by Ungar et al. with 380 patients included, death from any cause occurred in 35 (9.2\%) patients during the mean follow-up of 614 days. Death was considered cardiovascular in 9 patients (26\%). And among the patients who died, $82 \%$ were older and had cardiac risk factors such as abnormal ECG and/or heart disease. In contrast, among those with no abnormal ECG and/or heart disease, only six (3\%) deaths occurred, resulting in a negative predictive value of 97\% (Ungar et al., 2010).

Another study of 200 patients with syncope, cardiac origin was associated with adverse events defined as death, recurrence of syncope, cardiovascular events, and major procedures during the following short-term ( 1 month) and long (1 year) (Numerosos et al., 2013).

A study of 37,017 patients with syncope in the period 2001-2009, without previous hospitalization for comorbidities, and with a control group of 185,085 individuals, demonstrated increased risk of all-cause mortality, stroke, cardiovascular hospitalization, device implantation, and recurrent syncope in healthy individuals after first admission for syncope (Ruwald et al., 2013). Another study more recent from the same team, with 70,819 patients hospitalized between 2001 and 2009, aged between 19 and 90 years, with a mean follow up of 3.9 years, showed that recurrence of syncope, which occurred in $16.4 \%$, was associated to 3.2 times the risk of death within a year (Ruwald et al., 2014).

Regarding the recurrence of syncope, risk stratification cannot predict it. The incidence of recurrence of syncope was similar regardless of cause of syncope. Its rate was $0.3 \%$ in the first month, of $0.8 \%$ per month during the first year and $0.5 \%$ per month during the second year. On univariate analysis, predictors of recurrence were male sex, presence of prodrome and absence of palpitations (Ungar et al., 2010). On the other hand, the number of vasovagal syncope events in the preceding year may be a predictor of recurrence. Those patients with less than two previous episodes, the recurrence was $22 \%$ vs. $69 \%$ those with more than 6 episodes, with a probability of 46\% (Sumner et al., 2010).

Thus, prognosis is determined by the underlying etiology specifically the presence and severity of cardiac disease. And it is imperative to identify its cause and risk stratification for positive impact in reducing morbidity and mortality.

\section{REFERENCES}

Alboni, P., Brignole, M., Menozzi, C., Raviele, A., Del Rosso, A., Dinelli, M., et al (2001). Diagnostic value of history in patients with syncope with or without heart disease. J. Am. Coll. Cardiol. 37, 1921-1928. doi: 10.1016/S0735-1097(01) 01241-4

Azhar, C., and Lipsitz, L. A. (1998). "Syncope in the elderly," in Syncope: Mechanisms and Management, eds B. P. Grubb and B. Olshansky (New York, NY: Futura Publishing Company), 73-106.

Brignole, M., Menozzi, C., Bartoletti, A., Giada, F., Lagi, A., Ungar, A., et al. (2006). A new management of syncope: prospective systematic guideline-based evaluation of patients referred urgently to general hospitals. Eur. Heart J. 27, 76-82. doi: 10.1093/eurheartj/ehi647

Colman, N., Nali, K., Ganzeboom, K. S., Shen, W. K., Reitsma, J., Linzer, M., et al. (2004). Epidemiology of reflex syncope. Clin. Auton. Res. 14(Suppl. 1), i9-i17. doi: $10.1007 /$ s10286-004-1003-3 
Goldstein, D. S., and Sharabi, Y. (2009). Neurogenic orthostatic hypotension: a pathophysiological approach. Circulation 119, 139-146. doi: 10.1161/CIRCULATIONAHA.108.805887

Healey, J., Connolly, S. J., and Morillo, C. A. (2004). The management of patients with carotid sinus syndrome: is pacing the answer? Clin. Auton. Res. 14(Suppl. 1), 80-86. doi: 10.1007/s10286-004-1012-2

Kapoor, W. N. (2002). Current evaluation and management of syncope. Circulation 106, 1606-1609. doi: 10.1161/01.CIR.0000031168.96232.BA

Lewis, D. A., and Dhala, A. (1999). Syncope in pediatric patient. Pediatr. Clin. North Am. 46, 205-219. doi: 10.1016/S0031-3955(05)70113-9

Lewis, T. (1932). A lecture on vasovagal syncope and the carotid sinus mechanism. Br. Med. J. 873-876. doi: 10.1136/bmj.1.3723.873

Lipsitz, L. A., Wei, J. Y., and Rowe, J. W. (1985). Syncope in an elderly institutionalized population: incidence, prevalence and associated risk. Q. J. Med. 55, 45-54.

Luciano, G. L., Brennan, M. J., and Rothbberg, M. B. (2010). Postprandial hypotension. Am. J. Med. 123, e1-e6. doi: 10.1016/j.amjmed.2009.06.026

Medow, M. S., Stewart, J. M., Sanyal, S., Mumtaz, A., Sica, D., and Frishman, W. H. (2008). Pathophysiology, diagnosis and treatment of orthostatic hypotension and vasovagal syncope. Cardiol. Rev. 16, 4-20. doi: 10.1097/CRD.0b013e3181 $5 c 8032$

Moya, A., Sutton, R., Ammirati, F., Blanc, J. J., Brignole, M., Dahm, J. B., et al. (2009). Guidelines for the diagnosis and management of syncope. Eur. Heart J. 30, 2631-2671. doi: 10.1093/eurheartj/ehp298

Numerosos, F., Mossini, G., Lippi, G., and Cervellin, G. (2013). Evaluation of the current progno-stic role of cardiogenic syncope. Intern. Emerg. Med. 8, 69-73. doi: 10.1007/s11739-012-0889-3

Osiro, S., Zurada, A., Gielecki, J., Shoja, M. M., Tubbs, R. S., and Loukas, M. (2012). A review of subclavian steal syndrome with clinical correlation. Med. Sci. Monit. 18, RA57-RA63. doi: 10.12659/MSM.882721

Potter, B. J., and Pinto, D. S. (2014). Subclavian steal syndrome. Circulation 129, 2320-2323. doi: 10.1161/CIRCULATIONAHA.113.006653

Raj, S. R., and Coffin, S. T. (2013). Medical therapy and physical maneuvers in the treatment of the vasovagal syncope and orthostatic hypotension. Prog. Cardiovasc. Dis. 55, 425-433. doi: 10.1016/j.pcad.2012.11.004

Rosanio, S., Schwarz, E. R., Ware, D. L., and Vitarelli, A. (2013). Syncope in adults: systematic review and proposal of a diagnostic and therapeutic algorithm. Int. J. Cardiol. 162, 149-157. doi: 10.1016/j.ijcard.2011.11.021

Ruwald, M. H., Hansen, M. L., Lamberts, M., Hansen, C. M., Vinther, M., Køber, L., et al. (2013). Prognosis among healthy individ-uals discharged with a primary diagnosis of syncope. J. Am. Coll. Cardiol. 61, 325-332. doi: 10.1016/j.jacc.2012.08.1024
Ruwald, M. H., Numé, A. K., Lamberts, M., Hansen, C. M., Hansen, M. L., Vinther, M., et al. (2014). Incidence and influence of hospitalization for recurrent syncope and its effect on short- and long-term all-cause and cardiovascular mortality. Am. J. Cardiol. 113, 1744-1750. doi: 10.1016/j.amjcard.2014.02.035

Serletes, A., Rose, S., Sheldon, A. G., and Sheldon, R. S. (2006). Vasovagal syncope in medical students and their first-degree relatives. Eur. Heart J. 27, 1967-1970. doi: 10.1093/eurheartj/ehl147

Sheldon, R., Rose, S., Connolly, S., Ritchie, D., Koshman, M. L., and Frenneaux, M. (2006). Diagnostic criteria for vasovagal syncope based on a quantitative history. Eur. Heart J. 27, 344-350. doi: 10.1093/eurheartj/ehi584

Soteriades, E. S., Evans, J. C., Larson, M. G., Chen, M. H., Chen, L., Benjamin, E. J., et al. (2002). Incidence and prognosis of syncope. N. Engl. J. Med. 347, 878-885. doi: 10.1056/NEJMoa012407

Sumner, G. L., Rose, M. S., Koshman, M. L., Ritchie, D., Sheldon, R. S., and Prevention of Syncope Trial Investigators. (2010). Recent history of vasovagal syncope in a young, referral-based population is a stronger predictor of recurrent syncope than lifetime syncope burden. J. Cardiovasc. Electrophysiol. 21, 1375-1380. doi: 10.1111/j.1540-8167.2010.01848.x

Sun, B. C. (2013). Quality-of-life, health service use, and costs associated with syncope. Prog. Cardiovasc. Dis. 55, 370-375. doi: 10.1016/j.pcad.2012.10.009

Ungar, A., Del Rosso, A., Giada, F., Bartoletti, A., Furlan, R., Quartueri, F., et al. (2010). Evaluation of guidelines of syncope study 2 group. Early and late outcomeof treated patients referred for syncope to emergency department: the EGSYS2 follow-up study. Eur. Heart J. 31, 2021-2026. doi: 10.1093/eurheartj/ehq017

Conflict of Interest Statement: The author declares that the research was conducted in the absence of any commercial or financial relationships that could be construed as a potential conflict of interest.

Received: 31 October 2014; paper pending published: 05 November 2014; accepted: 17 November 2014; published online: 08 December 2014

Citation: da Silva RMFL (2014) Syncope: epidemiology, etiology, and prognosis. Front. Physiol. 5:471. doi: 10.3389/fphys.2014.00471

This article was submitted to Striated Muscle Physiology, a section of the journal Frontiers in Physiology.

Copyright (C) 2014 da Silva. This is an open-access article distributed under the terms of the Creative Commons Attribution License (CC BY). The use, distribution or reproduction in other forums is permitted, provided the original author(s) or licensor are credited and that the original publication in this journal is cited, in accordance with accepted academic practice. No use, distribution or reproduction is permitted which does not comply with these terms. 